\title{
Programme on Ecosystem Change and Society: Knowledge for sustainable stewardship of social-ecological systems
}

\author{
Albert V. Norström $^{1}$, Patricia Balvanera ${ }^{2}$, Marja Spierenburg $^{3,4}$ and $_{\text {Meriem Bouamrane }}^{5}$
}

\section{WHAT IS THE PROGRAMME ON ECOSYSTEM CHANGE AND SOCIETY?}

The Programme on Ecosystem Change and Society (PECS) is an international research program with a focus on social-ecological systems and how we can transform them towards sustainable pathways. PECS has emerged in a time where many advances in sustainability science and practice are being inspired by socialecological research (Fischer et al. 2015). While work on the interplay between nature and society has a long history and multiple interpretations (Brondizio 2016, Folke et al. 2016) the concept of social-ecological systems was introduced by Berkes and Folke (1998) as an integrated view of humans-in-nature. In essence this research highlights that people are part of ecosystems and shape them, from local to global scales, and are at the same time fundamentally dependent on these systems to provide services for human wellbeing and societal development. In 2005 The Millennium Ecosystem Assessment (MA) helped mainstream this approach, while also revealing significant gaps in the scientific knowledge on the dynamics of social-ecological systems. In 2008, an expert group established by the International Council for Science (ICSU) and partners recommended the establishment of a research program that could deal with these knowledge gaps (Carpenter et al. 2009). The result was the Programme on Ecosystem Change and Society (PECS), which was established in 2011 and is hosted by the Stockholm Resilience Centre. Since the beginning of 2014 PECS is officially part of Future Earth, the newly created global research platform that aims to provide the knowledge and support to accelerate our transformations to a sustainable world.

PECS research follows two broad approaches (Carpenter et al. 2012). The main approach is comparisons of place-based (research that addresses the particularities of specific landscapes, seascapes, or coastal regions) and social-ecological (interdependent and linked systems of people and nature) case studies from around the world. PECS has been growing steadily over the past four years, and has endorsed 21 projects that together encompass 42 case studies. These projects represent a wide range of social and environmental situations across the planet. PECS provides the mechanisms for intellectual exchange and learning among these diverse projects and fosters comparison among sites as well as strategies for better understanding the connections between local realities and the global interconnections. The second approach is the development of a set of dynamic, interdisciplinary working groups that focus on different cross cutting topics. These working groups can be seen as the PECS "fast-track" research activities that often build on, but are not limited to, the endorsed PECS place-based case studies.
While there has been progress in understanding how environmental, economic, and societal change processes are dynamically interlinked, the pertinent conservation and development challenges of the 21 st century are immense (Reid et al. 2010). The expansion of the human dimension into the Anthropocene has resulted in an interconnected global society with new cross-scale interactions connecting people and places in new ways (Steffen et al. 2011). Furthermore, the MA and other international research projects have shown that many ecosystem services are in decline as a consequence of institutional failures (Walker et al. 2009) and rapid regional and global change that has increased social and environmental stresses, shocks, and surprises (Rockström et al. 2009). There is a real danger that these challenges will outpace our efforts to transform towards sustainable stewardship of social-ecological systems. It is therefore critical that PECS and other similar networks can provide future motivation and stimuli for social-ecological research and practice in areas where progress is most urgently needed.

\section{THIS SPECIAL FEATURE}

\section{Place-based, social-ecological research}

This special feature includes papers produced by researchers and practitioners from the PECS network. It provides an initial overview of the research being carried out in some of the different PECS projects and working groups.

One key feature of many PECS projects is a focus on understanding how multiple ecosystem services are coproduced by social and ecological factors, and how management and governance of ecosystem services can support the fostering of social-ecological resilience and human wellbeing. Along these lines, Meacham et al. (2016) explore how different social and ecological factors explain the availability and distribution of ecosystem service bundles (reasonably coherent sets of ecosystem services in a landscape or seascape) in the Norrström drainage basin in Sweden. The authors develop four different models of human impact based on established theories of humanenvironmental interactions (land use, ecological modernization, ecological footprint, and location theory), and use those to predict ecosystem service bundles in the region. Their findings suggest that ecosystem service assessments could be improved by adopting a more social-ecological approach that integrates multiple social, geographical, and ecological theories, and utilizes diverse types of data. Similarly, Garciá-Llorente et al. (2015) reveal the importance of considering both biophysical (e.g., green freshwater flows) and socio-cultural (e.g., traditional irrigation canals) factors when assessing ecosystem services in two semiarid

${ }^{1}$ Stockholm Resilience Centre, Stockholm University, Sweden, ${ }^{2}$ Instituto de Investigaciones en Ecosistemas y Sustentabilidad, Universidad Nacional Autónoma de México, ${ }^{3}$ Radboud University Nijmegen, ${ }^{4}$ Stellenbosch University, ${ }^{5}$ UNESCO-MAB 
watersheds in southeast Spain. Furthermore, their work in the Adra and the Nacimiento regions, both located in the Almeria and Granada provinces, also provides a novel assessment of the trade-offs that exist between the factors that generate, or may influence, the supply and demand of ecosystem services. They show that land-use intensification generally resulted in losses of the biophysical factors that underpin the supply of some ecosystem services, increases in social demand for less diversified services, and the abandonment of local governance practices.

Place-based sustainability issues are particularly pressing in the context of rapidly suburbanizing areas. Two of the papers in this feature focus on such a region - the agricultural Montérégie landscape just east of Montreal, Québec, Canada. RaudseppHearne and Peterson (2016) systematically investigate how ecosystem services are produced, used, and managed at different scales, and how this matters for ecosystem service assessments and for managers. By analyzing how the scale of observation affects results by mapping services at three different spatial scales, they demonstrate that although there is consistency in trade-offs and synergies among ecosystem services across scales, changes in the scale of observation alters the bundles of ecosystem services that are identified in a landscape. They identify four types of scale mismatches in their landscape: two between production and benefit distribution, and two between ecosystem management and production. Mitchell et al. (2015) investigate how current and historic landscape structure influences ecosystem service provision in the region. Their results suggest that landscape management decisions need to take into account landscape structure - such as connectivity and fragmentation - to effectively manage ecosystem services. Furthermore, by using novel historical analyses the authors show that historical legacies of land use and land cover can significantly influence current ecosystem functioning and ecosystem provision. By plugging their results into four future scenarios for the region, they explore how land-use decisions could affect ecosystem service provision and human well-being across the region to the year 2045 .

Several PECS projects are applying participatory scenarios to assess local and regional social-ecological dynamics. Carpenter et al. (2015) develop four divergent trajectories for the agricultural and rapidly urbanizing Yahara watershed (southern Wisconsin, USA) to the year 2070, including a hypothetical collapse scenario, which is contrasted by scenarios emphasizing technological development, governance intervention, and shifting values. The authors recognize that scenarios are difficult to replicate as a research method, but highlight how useful they can be in exploring how different drivers, such as climate change, could play out in the watershed and conclude that scenarios will continue to be a useful tool for future social-ecological research. Hanspach et al. (2014) use participatory scenarios to explore, identify, and analyze alternative social-ecological futures in Southern Transylvania. They first apply a holistic approach to combine the local socialecological conditions throughout the study area with a description of the regional system dynamics and a spatially explicit understanding of current development trends for eight different variables (e.g., land use intensification, forest exploitation, emigration). Four scenarios for the region were developed through a series of scenario planning workshops, and reflect the influence of the most important (and most uncertain) drivers for the future of Southern Transylvania. Importantly, the results highlight that current conditions and trends are strongly influenced by legacies, i.e., past conditions and changes in the system. Further, they show the importance of external drivers (EU and national policy settings) for future developments and finally, how the influence of these external drivers can be amplified or counteracted by internal factors (education, leadership, and bridging organizations).

While the concept of well-being is becoming increasingly central to research and policy on ecosystem services, significant gaps remain in our understanding of how ecosystems actually contribute to different people's well- being and to alleviation of poverty. Daw et al. (2016) use the concept of "ecosystem service elasticity" to develop a framework that describes the sensitivity of human well-being to changes in ecosystem services. The framework places multidimensional well-being of different people as the final element, and emphasizes how different people access ecosystem service benefits and how these benefits match their needs or aspirations. The authors apply this framework to case studies of individual coastal ecosystem services in East Africa and illustrate a wide range of social and ecological factors that can affect ecosystem service elasticity. Applying this framework across different ecosystem services, contexts, and for different people could advance both ecosystem services theory and provide practical guidelines for pursuing environmental management for human well-being and poverty alleviation.

Other PECS projects are focusing on developing other novel methods to assess the resilience of place-based social-ecological systems. For instance, Luthe and Wyss (2016) use a detailed social network approach to assess the resilience of three municipalities in the Swiss Surselva-Gotthard region to gradual and fast climate change. The three focal municipalities in this region - Andermatt, Sedrun and Disentis - are all strongly dependent on the tourism sector in winter, while their economic development is closely linked to the short-term variability and long-term trend of the regional and local climate. In this study, the authors use the approach to assess resilience across different governance scales to provide policy implications. The authors conclude that while individual municipalities have the capacity to deal extreme events, resilience against the generally slower developing trends and impacts of climate change require governance structures that link different municipalities.

\section{Comparisons across cases and social-ecological systems}

Comparisons across scales and social-ecological systems are at the core of the PECS approach. This special feature provides examples of some of the initial key comparisons and syntheses that have been generated across PECS case-studies and projects.

For example, Balvanera et al. (2016) surveyed the leaders of 25 PECS affiliated projects (spanning 42 social-ecological study cases across 25 countries) to identify the key features that contribute towards successful research design and implementation of place-based social-ecological sustainability research (PBSESR). The study confirms a number of earlier findings on the particular opportunities such as the importance of focusing on solution and transformation-oriented research, adapting the research questions to the local social-ecological context, and having frequent engagement with stakeholders and partners. It also confirms on consistent challenges including the complexities inherent to social-ecological systems, the need for long periods of 
time to initiate and conduct this kind of research and power asymmetries both within the research team and among stakeholders. The authors suggest five sets of recommendations regarding strategies to foster the success of PBSESR, that include the key role of learning from failures and merging international as well as locally relevant perspectives through inclusive approaches that actively reward respectful and collaborative behaviors within the scientific community.

Other comparisons across the PECS network focus on the application of a specific methodology. As highlighted by several papers in this special feature (Hanspach et al. 2014, Carpenter et al. 2015, Mitchell et al. 2015) participatory scenario planning is an increasingly popular tool in place-based environmental research for evaluating alternative futures of social-ecological systems. Oteros-Rozas et al. (2015) review 23 cases of participatory scenario planning in a wide range of case-studies affiliated to PECS. They find that the tool has enriched management and research of social-ecological systems by, for example, creating a dialogue between diverse knowledge systems, and raising stakeholders' awareness of drivers of change that require long-term planning. However, in many cases the longerterm potential of scenario planning to promote collective action is still not known, because of a lack of systematic evaluation and monitoring. The authors see this paper as a starting point to build an international community of practice that can share methods, issues, and insights in order to improve the practice of participatory scenario planning, for example within the IPBES's assessments of ecosystem services and biodiversity.

Another cross-case comparison in this special feature provides insights on how to close the gap between science and practice when carrying out ecosystem service assessments. Förster et al. (2015) present a problem-oriented approach that aligns ecosystem service assessments to the specific information needs by decision makers. The approach builds on the analysis of empirical experience of four place-based ecosystem service assessments and a multitude of existing ecosystem service frameworks. Their results highlight the need to identify key issues and needs by decision makers from the outset of the assessment process, and focus on decision-relevant ecosystem service information throughout the assessment process. Engagement of relevant stakeholders and the building of trust between stakeholder groups and the integration of ecosystem service assessments into ongoing policy processes are thus needed.

Cundill et al. (2015) use insights gained from the literature on situated learning and three case-studies, to introduce the concept of transdisciplinary communities of practice (TDCOP). The authors provide three key lessons for people working in, managing, or funding such groups. Firstly, opportunities need to be purposefully created for outsiders to observe activities in the core group. Such peripheral participation can play an important role in creating opportunities for the membership of TDCOPs to be expanded, for ideas to spread beyond the core group and to enhance the reputation of the TDCOP. Secondly, communities of practice cannot be artificially created, but they can be nurtured. They are emergent social phenomena resulting from interactions among diverse groups and stakeholders that must arise out of the concerted efforts and shared interests of the individuals and social groups involved. Finally, the authors conclude that power matters in transdisciplinary communities of practice. Power asymmetries can prevent some actors from playing an active role in TDCOP and can result in banishing some participants to the periphery with little prospect of joining the core group.

\section{Coordinating international social-ecological research}

Finally, this special feature also provides an intellectual platform for other large international research networks to share insights and identify critical opportunities for coordinated regional socialecological research. In particular, the International Long-Term Ecological Research (ILTER) that has increasingly begun to expand its research activities beyond conservation areas and adopt a place-based long-term socio-ecological research approach. Maass et al. (2016) focus on a subset of 15 ILTER sites that provide a broad cross-section of contrasting social-ecological systems with different policy and management settings, distinct trends of biodiversity change, different stakeholders' preferences for ecosystem services and diverse components of well-being issues. The authors propose a conceptual approach linking ecosystem integrity, ecosystem services, and stakeholder wellbeing that could also analyze trade-offs among ecosystem services inherent in diverse management options. The paper outlines a methodological approach which includes: i) monitoring and synthesis activities following spatial and temporal trends and changes on each site and by documenting cross-scale interactions; ii) developing analytical tools for integration; iii) promoting transsite comparison; and iv) developing conceptual tools to design adequate policies and management interventions to deal with trade-offs.

Another large network with clear links to PECS is the Man and the Biosphere (MAB) Programme of UNESCO. Biosphere reserves were conceived as examples of sustainable socialecological systems. They are designed to combine biodiversity conservation with socio-economic development and knowledge (both scientific and local knowledge) production and dissemination. However, in practice, the implementation and combination of these different functions is quite challenging. Boumrane et al. (2016), based on several case studies of Biosphere reserves, provide insights into key social and ecological processes that either lead to or hamper building engagement and knowledge to achieve sustainable development in socio-ecological systems, highlighting the importance of involving stakeholders right from the start of the process of designing the reserves. They also propose a number of tools to stimulate the cooperation between different knowledge holders - including local communities.

Plieninger et al. (2015), argue that the long tradition of landscape research in Europe can inform projects such as PECS. The authors conclude that landscapes are a useful boundary object in studying complex interactions between human activities and the environment and an intuitive analytical unit of social-ecological research. The review shows that drivers such as agricultural industrialization and urbanization, as well as the preservation approach to landscape governance, have led to a fundamental decoupling of humans and the environment in landscapes. Using insights from landscape research is important, since they can help identify options for recoupling of social and ecological subsystems and develop visions for sustainable stewardship. The authors highlight that concepts such as landscape stewardship focus on the simultaneous improvement of food production, 
biodiversity or ecosystem conservation, cultural heritage preservation, and human well-being, rather than on the maximized production of an individual ecosystem good or service. It also offers lessons in self-organization of communities and stakeholder participation, including people not only as variables affecting landscapes but also as stewards of those landscapes, supporting adaptive, collaborative management within a social learning framework.

\section{CONCLUSION}

The vision of PECS is a world where human actions are transformed to achieve sustainable stewardship of socialecological systems. The goal of PECS is to generate the scientific and policy-relevant knowledge of social-ecological dynamics needed to enable such a shift, including mitigation of poverty. In this special feature we have shown how PECS projects and case studies can contribute towards that end.

All of PECS initiatives have high levels of engagement and collaboration with people from outside academia. This type of research is often referred to as being transdisciplinary, or "codesigned". PECS can help understand how such research is initiated and framed, how to involve stakeholders outside academia, what new methods contribute to achieving such integration, and what type of outreach and communication is relevant and generates impact.

The impact of PECS is enhanced through its membership of large global sustainability research platforms such as Future Earth. What is exciting about Future Earth is that it is, in essence, a network of networks aimed at intensifying the impact of research and finding new ways to promote sustainable development at global, regional, national, and local levels. Just like Future Earth, PECS explicitly recognizes that human activities have already transformed the Earth system. Furthermore, both Future Earth and PECS stimulate research that supports deliberate transitions and transformations towards global sustainability.

PECS will continue to contribute cutting-edge research on socialecological dynamics that either facilitate or prevent these types of transformations. One example of a positive contribution is the "Seeds of a Good Anthropocene" project - which is run together with ecoSERVICES - which aims to counterbalance current dystopic visions of the future by identifying elements of a Good Anthropocene currently existing on the planet, and study how these seeds grow into new, positive futures for the Earth and humanity. Seeds are being solicited by actively approaching different communities of research and practice around the world, and through a blog (http://goodanthropocenes.net) that allows such communities to draw attention to new seeds. Unlike many other Future Earth projects, which try to downscale from the global, PECS builds up from the local. The focus of PECS on place-based, long-term social-ecological case studies can greatly contribute to making Future Earth research regionally and locally relevant. We contribute and are part of an interconnected global society with cross-scale interactions connecting people and places in new ways. PECS research can help to better understand socialecological interactions between regions, and across large distances; as well as the institutional and governance contexts in which they operate.

Ultimately, the success of PECS will depend on the participation of excellent projects and researchers who are motivated to link their research to the PECS network. For more information visit www.pecs-science.org

\section{A CONTINUED DISCUSSION}

We encourage readers to use the discussion page set up by Ecology and Society for this guest editorial to comment on the Special Feature and continue the discussion begun here. All types of input are welcome, from simple comments and queries to more formal commentaries and we would warmly welcome all who want to engage in the discussion.

Responses to this article can be read online at: http://www.ecologyandsociety.org/issues/responses. $\mathrm{php} / 9010$

\section{Acknowledgments:}

We thank the whole of the PECS community for their enthusiasm, support and creative work. We are grateful for support by grants from ICSU, Future Earth, the Beijer Foundation, the Erling-Persson Family Foundation, Marianne and Marcus Wallenberg Foundation, as well as from Mistra for core funding and Sida for the GRAID programme of the Stockholm Resilience Centre.

\section{LITERATURE CITED}

Balvanera, P., T. M. Daw, T. Gardner, B. Martín-López, A. Norström, C. Ifejika Speranza, M. Spierenburg, E. M. Bennett, M. Farfan, M. Hamann, J. N. Kittinger, T. Luthe, M. Maass, G. D. Peterson, and G. Pérez-Verdin. 2017. Key features for more successful place-based sustainability research on social-ecological systems: a Programme on Ecosystem Change and Society (PECS) perspective. Ecology and Society 22(1):14. http://dx.doi. org/10.5751/es-08826-220114

Berkes, F., and C. Folke. 1998. Linking social and ecological systems: Management practices and socialmechanisms for building resilience. Cambridge University Press, Cambridge.

Bouamrane, M., M. Spierenburg, A. Agrawal, A. Boureima, M.C. Cormier-Salem, M. Etienne, C. Le Page, H. Levrel, and R. Mathevet. 2016. Stakeholder engagement and biodiversity conservation challenges in social-ecological systems: some insights from biosphere reserves in western Africa and France. Ecology and Society 21(4):25. http://dx.doi.org/10.5751/ es-08812-210425

Brondizio, E. S. 2016. Entangled Futures: Anthropology's Engagement with Global Change Research. Anthropology and Climate Change: From Actions to Transformations.

Carpenter, S. R., E. G. Booth, S. Gillon, C. J. Kucharik, S. Loheide, A. S. Mase, M. Motew, J. Qiu, A. R. Rissman, J. Seifert, E. Soylu, M. Turner, and C. B. Wardropper. 2015. Plausible futures of a social-ecological system: Yahara watershed, Wisconsin, USA. Ecology and Society 20(2):10. http://dx.doi. org/10.5751/es-07433-200210

Carpenter, S. R., C. Folke, A. Norström, O. Olsson, L. Schultz, B. Agarwal, P. Balvanera, B. Campbell, J. C. Castilla, W. Cramer, R. DeFries, P. Eyzaguirre, T. P. Hughes, S. Polasky, Z. Sanusi, R. Scholes, and M. Spierenburg. 2012. Program on ecosystem change 
and society: an international research strategy for integrated social-ecological systems. Current Opinion in Environmental Sustainability 4(1):134-138. http://dx.doi.org/10.1016/j.cosust.2012.01.001

Carpenter, S. R., H. A. Mooney, J. Agard, D. Capistrano, R. S. DeFries, S. D'iaz, T. Dietz, A. K. Duraiappah, A. Oteng-Yeboah, H. M. Pereira, and others. 2009. Science for managing ecosystem services: Beyond the Millennium Ecosystem Assessment. Proceedings of the National Academy of Sciences 106 (5):1305-1312. http://dx.doi.org/10.1073/pnas.0808772106

Cundill, G., D. J. Roux, and J. N. Parker. 2015. Nurturing communities of practice for transdisciplinary research. Ecology and Society 20(2):22. http://dx.doi.org/10.5751/es-07580-200222

Daw, T. M., C. Hicks, K. Brown, T. Chaigneau, F. JanuchowskiHartley, W. Cheung, S. Rosendo, B. Crona, S. Coulthard, C. Sandbrook, C. Perry, S. Bandeira, N. A. Muthiga, B. SchulteHerbrüggen, J. Bosire, and T. R. McClanahan. 2016. Elasticity in ecosystem services: exploring the variable relationship between ecosystems and human well-being. Ecology and Society 21(2):11. http://dx.doi.org/10.5751/es-08173-210211

Folke, C., R. Biggs, A. V. Norström, B. Reyers, and J. Rockström. 2016. Social-ecological resilience and biosphere-based sustainability science. Ecology and Society 21(3):41. http://dx.doi.org/10.5751/ es-08748-210341

Förster, J., J. Barkmann, R. Fricke, S. Hotes, M. Kleyer, S. Kobbe, D. Kübler, C. Rumbaur, M. Siegmund-Schultze, R. Seppelt, J. Settele, J. H. Spangenberg, V. Tekken, T. Václavík, and H. Wittmer. 2015. Assessing ecosystem services for informing landuse decisions: a problem-oriented approach. Ecology and Society 20(3):31. http://dx.doi.org/10.5751/es-07804-200331

García-Llorente, M., I. Iniesta-Arandia, B. A. Willaarts, P. A. Harrison, P. Berry, M. del Mar Bayo, A. J. Castro, C. Montes, and B. Martín-López. 2015. Biophysical and sociocultural factors underlying spatial trade-offs of ecosystem services in semiarid watersheds. Ecology and Society 20(3):39. http://dx.doi. org/10.5751/es-07785-200339

Hanspach, J., T. Hartel, A. I. Milcu, F. Mikulcak, I. Dorresteijn, J. Loos, H. von Wehrden, T. Kuemmerle, D. Abson, A. KovácsHostyánszki, A. Báldi, and J. Fischer. 2014. A holistic approach to studying social-ecological systems and its application to southern Transylvania. Ecology and Society 19(4):32. http://dx. doi.org/10.5751/es-06915-190432

Luthe, T., and R. Wyss. 2016. Resilience to climate change in a cross-scale tourism governance context: a combined quantitativequalitative network analysis. Ecology and Society 21(1):27. http:// dx.doi.org/10.5751/es-08234-210127

Maass, M., P. Balvanera, P. Bourgeron, M. Equihua, J. Baudry, J. Dick, M. Forsius, L. Halada, K. Krauze, M. Nakaoka, D. E. Orenstein, T. W. Parr, C. L. Redman, R. Rozzi, M. Santos-Reis, A. M. Swemmer, and A. Vădineanu. 2016. Changes in biodiversity and trade-offs among ecosystem services, stakeholders, and components of well-being: the contribution of the International Long-Term Ecological Research network (ILTER) to Programme on Ecosystem Change and Society (PECS). Ecology and Society 21(3):31. http://dx.doi.org/10.5751/es-08587-210331

Meacham, M., C. Queiroz, A. V. Norström, and G. D. Peterson. 2016. Social-ecological drivers of multiple ecosystem services: what variables explain patterns of ecosystem services across the Norrström drainage basin? Ecology and Society 21(1):14. http:// dx.doi.org/10.5751/es-08077-210114

Mitchell, M. G. E., E. M. Bennett, A. Gonzalez, M. J. Lechowicz, J. M. Rhemtulla, J. A. Cardille, K. Vanderheyden, G. PoirierGhys, D. Renard, S. Delmotte, C. H. Albert, B. Rayfield, M. Dumitru, H.-H. Huang, M. Larouche, K. N. Liss, D. Y. Maguire, K. T. Martins, M. Terrado, C. Ziter, L. Taliana, and K. Dancose. 2015. The Montérégie Connection: linking landscapes, biodiversity, and ecosystem services to improve decision making. Ecology and Society 20(4):15. http://dx.doi.org/10.5751/ es-07927-200415

Oteros-Rozas, E., B. Martín-López, T. Daw, E. L. Bohensky, J. Butler, R. Hill, J. Martin-Ortega, A. Quinlan, F. Ravera, I. RuizMallén, M. Thyresson, J. Mistry, I. Palomo, G. D. Peterson, T. Plieninger, K. A. Waylen, D. Beach, I. C. Bohnet, M. Hamann, J. Hanspach, K. Hubacek, S. Lavorel and S. Vilardy 2015. Participatory scenario planning in place-based social-ecological research: insights and experiences from 23 case studies. Ecology and Society 20(4):32. http://dx.doi.org/10.5751/ES-07985-200432

Plieninger, T., T. Kizos, C. Bieling, L. Le Dû-Blayo, M.-A. Budniok, M. Bürgi, C. L. Crumley, G. Girod, P. Howard, J. Kolen, T. Kuemmerle, G. Milcinski, H. Palang, K. Trommler, and P. H. Verburg. 2015. Exploring ecosystem-change and society through a landscape lens: recent progress in European landscape research. Ecology and Society 20(2):5. http://dx.doi.org/10.5751/es-07443-200205

Raudsepp-Hearne, C., and G. D. Peterson. 2016. Scale and ecosystem services: how do observation, management, and analysis shift with scale-lessons from Québec. Ecology and Society 21(3):16 http://dx.doi.org/10.5751/ES-08605-210316

Reid, W. V., D. Chen, L. Goldfarb, H. Hackmann, Y. T. Lee, K. Mokhele, E. Ostrom, K. Raivio, J. Rockstrom, H. J. Schellnhuber, and A. Whyte. 2010. Earth system science for global sustainability: grand challenges. Science 330(6006):916-917. http://dx.doi.org/10.1126/science.1196263

Rockström, J., W. Steffen, K. Noone, E. Lambin, T. M. Lenton, M. Scheffer, C. Folke, H. J. Schellnhuber, C. A. De Wit, T. Hughes, S. Van Der Leeuw, H. Rodhe, P. K. Snyder, R. Costanza, U. Svedin, M. Falkenmark, L. Karlberg, R. W. Corell, V. J. Fabry, J. Hansen, B. Walker, D. Liverman, K. Richardson, P. Crutzen, and J. Foley. 2009. Planetary boundaries: exploring the safe operating space for humanity. Ecology and Society 14(2):32. http://dx.doi. org/10.5751/es-03180-140232

Steffen, W., Å. Persson, L. Deutsch, J. Zalasiewicz, M. Williams, K. Richardson, C. Crumley, P. Crutzen, C. Folke, L. Gordon, M. Molina, V. Ramanathan, J. Rockström, M. Scheffer, H. J. Schellnhuber, and U. Svedin. 2011. The Anthropocene: from global change to planetary stewardship. Ambio 40:739-761. http:// dx.doi.org/10.1007/s13280-011-0185-x

Walker, B., S. Barrett, S. Polasky, V. Galaz, C. Folke, G. Engström, F. Ackerman, K. Arrow, S. Carpenter, K. Chopra, G. Daily, P. Ehrlich, T. Hughes, N. Kautsky, S. Levin, K. Mäler, J. Shogren, J. Vincent, T. Xepapadeas, and A. de Zeeuw. 2009. Looming global-scale failures and missing institutions. Science 325:1345-1346. http://dx.doi.org/10.1126/science.1175325 